\title{
The Mode of Infection by Smut in Sugar-cane.
}

\author{
$B Y$ \\ JEHANGIR FARDUNJI DASTUR, M.Sc. \\ Supernumerary Mycologist, Pusa, India.
}

With ten Figures in the Text.

SUGAR-CANE smut (Ustilago Sacchari, Rabenh.) is well known in almost $N$ all the cane-growing countries, but as yet the exact details of the manner in which sugar-cane is infected with smut have not been worked out. $^{1} \quad$ Kruiger $^{2}$ and Delacroix and Maublanc ${ }^{3}$ believe that cane smut is not only produced by planting setts taken from infected parents, but also by direct infection of healthy plants. Wakker ${ }^{4}$ has observed that setts taken from stools grown in the neighbourhood of smutted Saccharum spontaneum gave a diseased crop, and therefore Delacroix and Maublanc suppose that the spores infected the setts, probably the buds. In Java, artificial inoculations on cut surface of the setts and also on the buds have given diseased shoots in about a year. Ajrekar, ${ }^{5}$ in Poona, succeeded in growing diseased shoots by planting setts after smearing them with spores. Dr. Butler, the Imperial Mycologist, in his unpublished notes, which he has very kindly allowed me to consult, says that he did not succeed in duplicating the results obtained in Java. He dipped, before planting, a hundred setts in water containing smut spores, and only one sett gave a smutted stool. My experiments show that the direct infection takes place only in two ways: (I) through very tender buds, (2) through old buds only when wounded. These results are in direct contradiction to those obtained in Java as far as the infection of setts through the cut ends is concerned. As regards direct infection there is discrepancy between the results obtained in Pusa, Java, and Poona, which perhaps can be explained in the light of the present work. It is possible that Dr. Butler, in Pusa, may have used setts from mature

1 Butler, E. J.: Fungi and Disease in Plants, p. 378, 1918.

2 Krüger, W.: Das Zuckerrohr und seine Kultur, p. 406, 1899.

3 Delacroix, G., and Maublanc, A.: Maladies des plantes cultivées dans les pays chands, p. $514,1911$.

4 Wakker : Archief voor de Java-Suikerindustrie, p. 929, 1895 .

- Ajrekar, S. L. : On the Mode of Infection and Prevention of the Snut Disease of Sugar-cane. Agr. Journ. India, xi, p. 292, 1916.

[Annals of Bo:any, Vo1. XXXIV. No. CXXXV. July, 1920.] 
canes or back setts; these setts had therefore old buds, and so the results were negative. But in Java, for the experiments which gave positive results, setts from immature cane or top setts may have been used, and these setts had consequently tender eyes. The Poona results may be explained in the same way, but unfortunately Ajrekar's experiments are not convincing. From his Experiment No. -2 we find that healthy setts unsteeped (plot No. 2) gave 122 smutted shoots and diseased setts, unsteeped (plot No. 4) gave 228 smutted shoots. No explanation is given as to how healthy setts became smutted to such a large extent. Again, in Experiment No. 4, 25 setts (plot No. 2), first smeared with spores and then steeped in I per cent. copper sulphate solution, gave only 25 smutted shoots, while plot No. 3, a duplicate of plot No. 2 in all respects, gave over 500 smutted shoots. It is difficult to explain the disparity between the results of those two plots, and therefore the value of the whole experiment is vitiated; and consequently from his experiments it cannot be definitely concluded 'infection by spores adhering to setts takes place'.

\section{INOCULATION EXPERIMENTS.}

For the inoculations either fresh spores were used or cultures grown on bread paste. This medium has been found to be very suitable for germinating smut spores. In twenty-four hours a thin white film of mycelium containing innumerable sporidia are found where spores have been planted. The infection through sporidia takes place naturally more quickly than with spores.

Unless where otherwise stated, cuttings and plants of the susceptible 'thin' varieties, Seretha and Mungo, have been used for inoculations.

Inoculations on the cut ends of the setts and on the top of the crown, cut back without damaging the growing-point, have been unsuccessful. Several attempts have been made to infect the cut ends of the setts, but all have so far proved unsuccessful. These setts were kept in moist chambers.

Infection of rootlets and root buds of setts kept in moist chambers have also proved unsuccessful. Setts incubated in moist chambers have been successfully inoculated through tender buds, the scale leaves of which had not turned brown. In some cases the infection takes so readily that in four days' time the mycelium reaches the growing-point (Fig. 2). Old buds which have become swollen and the scale leaves of which are hard and brown could only be inoculated when wounded. The wound did not reach the growing-point, but only slightly exposed the inner tender pale green scale leaves. All these experiments were microscopically controlled. The control setts invariably remained healthy.

The inoculations of setts done under moist-chamber conditions were duplicated on potted plants.

Some of the experiments are detailed below, 
If the bud to be inoculated was covered by the leaf-sheath, the latter was completely removed without injuring the bud. All the experiments had controls which invariably remained healthy.

Two very tender buds of a potted plant were inoculated by means of spores on June 22, I918, About two months later, August I5, the shoots developing from these inoculated buds had produced the characteristic spore-bearing whip-like prolongations. Three days later the shoot from below the inoculated bud was also smutted. Microscopic examination of the plant showed that its tissues were filled with smut hyphae.

Plants inoculated through wounded roots and root buds remained healthy and no hyphae were found in their tissues.

The crowns of a few plants were cut back without injuring the growingpoints and the tops of a few plants were completely removed, and the cut ends were inoculated with spores and with cultures on bread meal. All the infections failed.

On August 27, 1918, several plants were inoculated through tender wounded and unwounded buds. A month later sections were made of the small shoots arising from some of the inoculated buds. Smut hyphae were found in the growing-point and in the scale leaves. On November 6 , one of the inoculated buds gave a spore-bearing shoot. After this date spore-bearing shoots were produced from time to time till April 19I9.

One of the plants had all the inoculated buds except one removed for

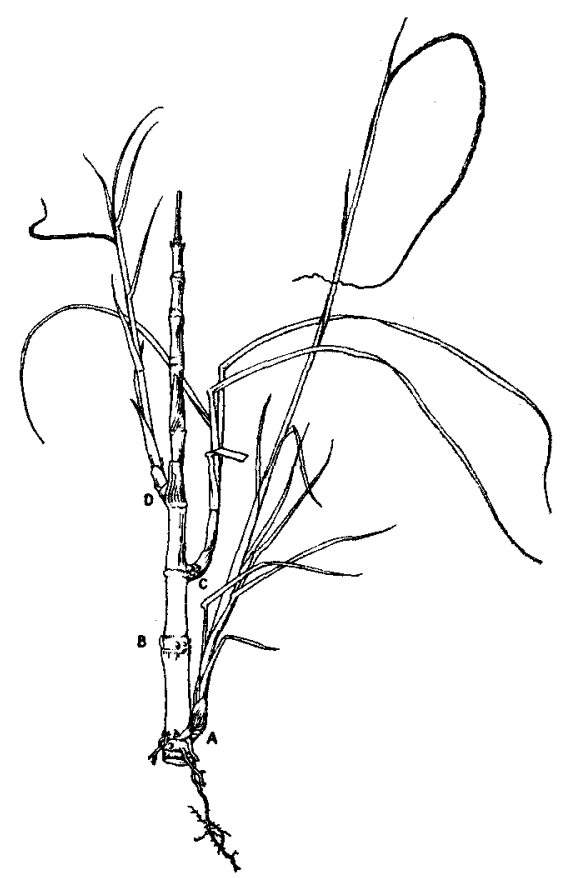

FIG. I. Inoculated sugar-cane plant, for microscopic examination. The uninoculated buds below and above the inoculated buds gave smutted shoots. The whole cane was found to contain smut hyphae. Some of the adventitious roots arising from nodes above ground level were found to have their cortical tissues infected with smut hyphae.

One plant (Fig. I) had only one bud (B) inoculated on August 27, 1918. This bud remained dormant till April 9, I919, when it was sectioned and was found to contain smut hyphae in its tissues. The mycelium from the inoculated bud entered the node and travelled up and down the stem, and from the stem passed into the other buds. The smut hyphae in the main 
stem was traced right up to the growing-point. The bud (c) on the node immediately above the inoculated bud showed signs of sprouting in the beginning of January 1919, and it died in the end of March. No sporebearing whip was produced. The bud (D) on the node above this dead shoot began to open in the middle of March and on April ro developed a spore-bearing shoot. The bud (A) below the inoculated dormant bud was seen to burst in the beginning of March, and on April 6 the characteristic spore-bearing shoot was visible. Rootlets arising from this node and from the node below it had smut hyphae in their cortical tissues.

At times the inoculated bud dies before it has grown into a shoot. In this dead bud are found smut hyphae; they can also be traced into the node and in the internodes above and below this node. The extent of the penetration of the hyphae depends upon the time that elapsed since the inoculation.

A ' thick' variety of cane, Purple Mauritius, was inoculated on January 33, 1919, through wounded buds. Some of the shoots from the wounded bud were sectioned on April 26; smut hyphae were found in their tissues. Inoculations through unwounded young and old buds were unsuccessful. Another 'thick' variety, Sathi I3I, was inoculated through wounded and unwounded tender buds on July 1,1919 , and the cuttings were incubated in moist chambers. On the $23 \mathrm{rd}$, the shoots from all the wounded inoculated buds were found on microscopic examination to be infected, but the shoots from the unwounded inoculated buds showed no signs of infection.

On April 10, 1919, (I) unwounded old buds, (2) wounded old buds, and (3) unwounded tender buds were inoculated with cultures of the smut on bread paste. Five weeks later some of the buds from each of these series were sectioned and nicroscopically examined; smut hyphae were found in the inoculated wounded old buds and in the unwounded tender buds, but not in the unwounded old buds.

Some of the unwounded tender and wounded old buds inoculated in August and November 1918 remained dormant, and the plants did not show any external signs of infection. These plants were cut into setts and those setts which had the dormant inoculated buds were planted in five pots on March 28, 1919. On April 20, a smutted shoot was produced by one of these setts, the buds of which were inoculated without wounding them on November 28. Two setts, which had unwounded inoculated buds, gave smutted shoots on June 18 and September 7,1919 . A fourth sett, which had wounded inoculated buds, was found smutted on June 19, 1919, and the fifth sett developed a smutted shoot on November 15,1919 . One plant was inoculated through its buds by wounding them on January ${ }_{13}$, 1919. The inoculated buds were dormant on April 28, when a cutting from this plant with the dormant inoculated buds was planted. On June I 7, I9I9, one of the shoots was found to produce a spore-bearing 'whip'. 


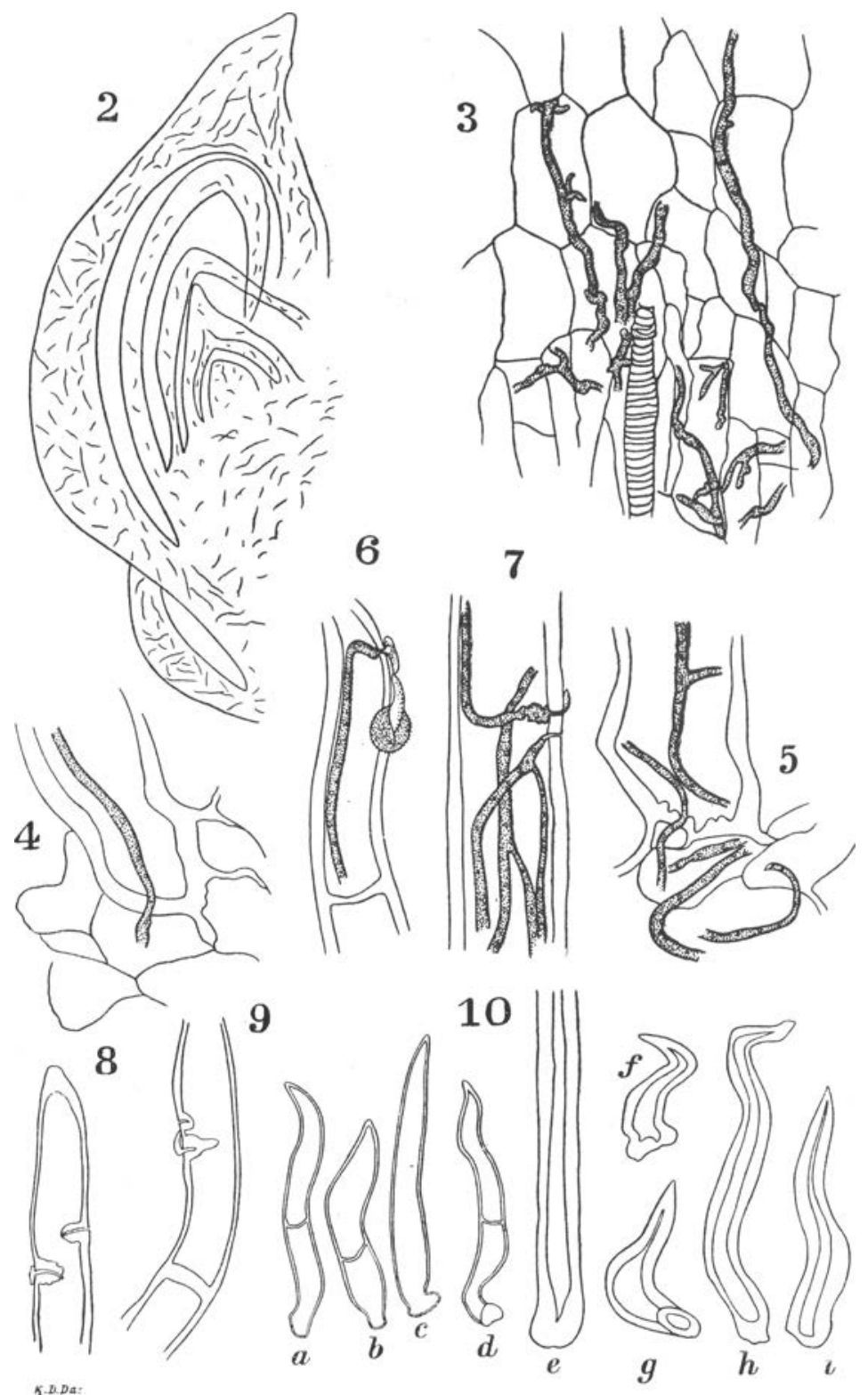

FIG. 2. Longitudinal section of an inoculated leaf-bnd showing the penetration of hyphae in four days. $\times 5 \mathbf{I}$.

FIG. 3. Longitudinal section of a scale leaf. $\times 357$.

FrGS. 4 and 5. Hyphae in the hairs of a scale leaf. $\times 368$. $\times 368$.

Figs. 6-9. Penetration of hairs by the germ-tube from sporidia. Fig. 6, $\times 550$; Figs. 7-9,

Fig. Io. Hairs from scale leaves: $a-d$, thin-walled hairs which are capable of being infected ; $e-i$, thick-walled hairs which cannot be infected. $\times 245$. 


\section{Dastur.-The Mode of Infection by Smut in Sugar-cane.}

Having established the fact that infection can take place through unwounded tender buds and through wounded old buds, the next step was to find the exact place through which the infecting germ-tube enters the host tissues. It was suspected that infection takes place through unthickened scale hairs, because the cavities of the hairs of the inoculated eye-buds were found to be filled with unseptate or very sparsely septate hyphae, and in some cases germ-tubes from what looked like sporidia were found to have penetrated the hairs.

Ultimately a few cases were found which conclusively proved that infection takes place through the scale hairs. In one particular case a spore had germinated on the surface of a thin hair and from the end of the promycelium a sporidium had developed. From this sporidium, which was still attached to the promycelium, a fine germ-tube was developed, which pierced the thin wall of the hair. In the lumen of the hair the fine germtube broadened and travelled downwards (Fig. 6).

Other very clear cases (Figs. 7-9) of sporidia penetrating the hairs of the scale leaves by means of their germ-tubes have been observed from time to time. At times the hair reacts to the entrance of the germ-tube by developing a plug or thickening on the inner wall (Figs. 8 and 9). Whether the plug prevents infection is not definitely known. A few cases, however, have been observed in which the germ-tube was found beyond the plug.

It is only the unthickened hair that the sporidium is capable of infecting (Fig. 10, $a-d$ ). Hairs with thickened walls (Fig. 10, $e-i$ ) have not been found to be infected, though spores and sporidia have been found to be lying on them. So far the germ-tube from the sporidium has not been observed to enter directly the epidermal cells.

Inside the hair, the hyphae from the sporidium give out branches which at times completely fill the lumen of the hair. From the basal part of the hair the hyphae enter adjacent epidermal and sub-epidermal cells (Figs. 4 and 5). In the tissues of the scale leaves the mycelium is intracellular and consists of long strands of hyphae which are sparsely septate (Fig. 3). In the young stem of the leaf-bud the mycelium is at first both inter- and intra-cellular, but ultimately it is chiefly intercellular. The mycelium from the outer scale leaf travels downwards, enters the young stem of the leaf-bud through the leaf base, thence it travels up the inner leaves and the growing-point and also enters the main stem through the node. In some cases the hyphae in the outer scale leaf directly enter the inner scale leaf, the outer epidermis of which is closely adpressed to the inner epidermis of the outer scale leaf.

\section{CONCLUSION.}

The experiments conclusively prove that direct infection of 'thin' varieties of cane can take place through tender buds, but not through old 
buds, unless wounded. 'Thick' varieties have been infected only through wounded eyes. So far as is known, the infection can take place only through unthickened scale hairs. The bud can produce a spore-bearing shoot within two months after infection. It is also evident that the hyphae from the infected bud, even when it remains dormant, travel into the main stem, thence to the tillers and secondary shoots, which ultimately may produce spore-bearing shoots. If from such a plant setts are used as 'seeds' before it produces spore-bearing shoots, which are the only visible sign of the presence of the disease, the new plants are bound to give infected stools, and setts containing inoculated buds which were dormant when planted have given smutted stools. These facts explain why setts taken from stools, which show no external sign of infection and look healthy in the absence of the spore-bearing shoots, give a new crop of smutted plants. It is therefore essential that setts used for inoculation experiments should be microscopically examined before they are inoculated.

\section{SUMMARY.}

It is shown that infection of the sugar-cane smut takes place only through the buds. The sporidia on germinating penetrate the young, thinwalled scale hairs. Infection through the cut ends of the setts does not take place.

A bud can produce a spore-bearing shoot within two months after infection. Diseased setts when planted give diseased shoots. 